\title{
Multiple Molecular Interactions Determine the Clustering of Caspr2 and Kv1 Channels in Myelinated Axons
}

\author{
Ido Horresh, ${ }^{1}$ Sebastian Poliak, ${ }^{1}$ Seth Grant, ${ }^{2}$ David Bredt, ${ }^{3}$ Matthew N. Rasband, ${ }^{4}$ and Elior Peles ${ }^{1}$ \\ ${ }^{1}$ Department of Molecular Cell Biology, The Weizmann Institute of Science, Rehovot 76100, Israel, ${ }^{2}$ The Wellcome Trust Sanger Institute, Hinxton, \\ Cambridge CB10 1SA, United Kingdom, ${ }^{3}$ Department of Integrative Biology, Eli Lilly and Company, Indianapolis, Indiana 46285, and ${ }^{4}$ Department of \\ Neuroscience, Baylor College of Medicine, Houston, Texas 77030
}

Clustering of Kv1 channels at the juxtaparanodal region (JXP) in myelinated axons depends on their association with the Caspr2/TAG-1 adhesion complex. The interaction between these channels and Caspr2 was suggested to depend on PDZ (PSD-95/Discs large/zona occludens-1) scaffolding proteins. Here, we show that at a subset of the JXP, PSD-93 colocalizes with Caspr2, $\mathrm{K}^{+}$channels and its related protein postsynaptic density protein-95 (PSD-95). The localization of PSD-93 and PSD-95 depends on the presence of Caspr2, as both scaffolding proteins failed to accumulate at the JXP in mice lacking either Caspr2 or TAG-1. In contrast, Caspr2 and $\mathrm{K}^{+}$channels still colocalized and associated in PSD-93, PSD-95 or double PSD-93/PSD-95 null mice. To directly evaluate the role of PDZ domain proteins in the function of Caspr2, we examined the ability of transgenic Caspr2 molecules lacking either their cytoplasmic domain (Caspr2dCT), or their PDZ-binding sequence (Caspr2dPDZ), to restore Kv1 channel clustering in Caspr 2 null mice. We found that while Kv1 channels were distributed throughout internodes in nerves expressing Caspr2dCT, they were clustered at the JXP in axons expressing a full-length Caspr2 (Caspr2FL) or the Caspr2dPDZ transgene. Further proteomic analysis revealed that Caspr2 interacts with a distinct set of scaffolding proteins through its PDZ- and protein 4.1-binding sequences. These results demonstrate that while the molecular assembly of the JXP requires the cytoplasmic domain of Caspr2, its carboxy-terminal PDZ-binding motif is dispensable for Kv1 channel clustering. This mechanism is clearly distinct from the one operating at the axon initial segment, which requires PSD-93 for Kv1 channel clustering.

Key words: nodes of Ranvier; axon initial segment; PSD-93; PSD-95; juxtaparanodes; scaffolding proteins

\section{Introduction}

The precise localization of ion channels to specialized sites along dendrites and axons is crucial for nervous system function. Myelinated axons exhibit distinct membrane domains at nodes of Ranvier and the axon initial segment (AIS) (Hedstrom and Rasband, 2006; Lai and Jan, 2006). These domains contain a unique set of protein complexes including, ion channels, cell adhesion molecules (CAMs) and cytoskeletal adapter proteins. At nodes, $\mathrm{Na}^{+}$and KCNQ2 $\mathrm{K}^{+}$channels are found together with $\beta \mathrm{IV}-$ spectrin and ankyrin $\mathrm{G}$ (ankG), as well as with the two Ig CAMs, $\mathrm{NrCAM}$ (neuron-glia-related CAM) and the $186 \mathrm{kDa}$ isoform of neurofascin (NF186) (Poliak and Peles, 2003; Salzer, 2003). A second domain, called the juxtaparanodal region (JXP), is found at the end of the compact myelin internodes. At this site, Shakerlike Kv1.1 and Kv1.2 $\mathrm{K}^{+}$channels are localized (Wang et al., 1993) and associated with an axonal cell adhesion complex con-

Received July 21, 2008; revised 0ct. 22, 2008; accepted Nov. 8, 2008.

This work was supported by the Dr. Miriam and Sheldon G. Adelson Medical Research Foundation, the National Multiple Sclerosis Society (Grant RG3594-A-4 to E.P.), the Wolgin Prize for Scientific Excellence (E.P.), and the National Institutes of Health (Grant NS044916 to M.N.R.). M.N.R. is a Harry Weaver Neuroscience Scholar of the National Multiple Sclerosis Society. We thank Allan Hall and Ben Margolis for MPP6 and MPP7 cDNA constructs; Rock Levinson, Andy Furley, Esther Stoeckli, and Jim Trimmer for antibodies; and the Smoler Proteomics Center at the Technion for their help.

Correspondence should be addressed to Dr. Elior Peles, Department of Molecular Cell Biology, The Weizmann Institute of Science, Rehovot 76100, Israel. E-mail: peles@weizmann.ac.il.

DOI:10.1523/JNEUROSCI.3398-08.2008

Copyright $\odot 2008$ Society for Neuroscience ～0270-6474/08/2814213-10\$15.00/0 sisting of Caspr2 and TAG-1 (Poliak et al., 1999, 2003; Traka et al., 2002, 2003). This JXP protein complex is separated from the nodal axolemma by the axoglial junction formed between the axon and the paranodal loops of oligodendrocytes and myelinating Schwann cells. In contrast to nodes and JXP, where voltagedependent $\mathrm{Na}^{+}$and $\mathrm{Kvl}$ channels are segregated into isolated membrane domains, these same channels partially overlap at the AIS (Hedstrom and Rasband, 2006; Inda et al., 2006). The AIS also contains all the other known nodal components: $\beta \mathrm{IV}$ spectrin (Berghs et al., 2000), ankG (Kordeli et al., 1995), KCNQ2 (Pan et al., 2006), the two axonodal CAMs (Davis et al., 1996), as well as the JXP components Kv1.2 and Caspr2 (Inda et al., 2006). Notably, despite their similar molecular organization, the mechanisms by which nodes and the AIS are formed appear to be distinct: while node formation requires myelination, the AIS is intrinsically organized by the neuron (Dzhashiashvili et al., 2007; Yang et al., 2007).

The localization of $\mathrm{K}^{+}$channels at the JXP requires axon-glia contact and involves two distinct mechanisms. First, it depends on a membrane barrier located at the paranodal junction (PNJ), which forms a gap between Kv1 channels and nodes of Ranvier. Disruption of the PNJ in several mutant mice (i.e., Caspr-, contactin- or cgt-null mice) results in the aberrant accumulation of Kv1 channels immediately adjacent to the nodes (Dupree et al., 1999; Bhat et al., 2001; Boyle et al., 2001; Poliak et al., 2001). Second, the Caspr2/TAG-1 adhesion complex functions to retain 
these channels at the JXP (Poliak et al., 2003; Traka et al., 2003). Previous studies suggested that the association between this CAM complex and Kv1 channels occurs indirectly through a PDZ (PSD-95/Discs large/zona occludens-1) domain-containing scaffolding protein which simultaneously binds to the carboxyterminal tail of Caspr2 and the $\alpha$ subunit of Kv1 channels (Kim et al., 1995; Poliak et al., 1999). To date, only one such PDZ domain-containing scaffolding protein, postsynaptic density protein-95 (PSD-95), was detected at the JXP (Baba et al., 1999). However, subsequent studies demonstrated that this protein is not required for the clustering of Kvl channels at this site (Rasband et al., 2002). Here, we use an in vivo knockout/rescue approach to elucidate the role of PDZ domain-containing proteins in the molecular assembly of the JXP.

\section{Materials and Methods}

Constructs and mice. Hemagglutinin (HA)-tagged constructs were all generated from human Caspr2 cDNA using PCR and standard cloning procedures: Caspr2-full-length-HA (C2FL), Caspr2dCT (C2dCT, deletion of the entire cytoplasmic tail from Y1285 and downstream) and Caspr2dPDZ (C2dPDZ, deletion of carboxy-terminal last four amino acids EWLI). In all constructs, the HA tag (amino acids YPYDVPDYAS) was inserted adjacent to the transmembrane domain between positions N1255-G1256. The modified cDNAs were cloned into a Thy1.2 expression cassette (Gollan et al., 2002), linearized, and introduced by pronuclear injection into fertilized eggs derived from $\mathrm{CB} 6 \mathrm{~F} 1$ mice. Pseudopregnant CD-1 outbred albino females were used as foster mothers for embryo transfer. Founder mice were genotyped by PCR using primers 5'-GCGTAGTCAGGCACATCGTATGGG-3' and 5'- GCGTAGTCAGGCACATCGTATGGG-3'. Founders were further crossed with CB6F1 mice and interbred to generate lines. Transgenic mice were routinely identified by PCR of tail genomic DNA, using the appropriate primers derived from human Caspr2 and HA-tag. The same primers were also used for RT-PCR analyses of RNA prepared from transgenicmice brains and dorsal root ganglia (DRG). Based on immunoprecipitation performed from brains of transgenic mice, two lines from each genotype were chosen and further crossed with Caspr2-null mice (Poliak et al., 2003). Generation and genotyping of Caspr2 ${ }^{-1-}, \mathrm{PSD}_{-} 93^{-1-}$, TAG-1 ${ }^{-1-}$ and PSD-95-deletion mutant mice have been described previously (Migaud et al., 1998; McGee et al., 2001; Rasband et al., 2002; Poliak et al., 2003). Control animals were derived from the same litters. All experiments were performed in compliance with the relevant laws and institutional guidelines and were approved by the Weizmann Institute's Institutional Animal Care and Use Committee. Myc-tag constructs: full-length MPP2 amplified from rat brain cDNA was cloned in frame with an N-terminal Myc tag; Myc-tagged MPP6/Pals2, MPP7 and $4.1 \mathrm{~B}$ were previously described (Kamberov et al., 2000; Gollan et al., 2002; Stucke et al., 2007).

Antibodies. Rabbit anti-Chapsyn 110 (PSD-93) antibodies were purchased from Alomone Labs and Millipore. Antibodies P6061 and P4344 directed to the intracellular region of Caspr or Caspr2, respectively, monoclonal antibody M275 directed against the extracellular domain of Caspr, as well as mouse serum that recognizes the extracellular region of Caspr2 have been previously described (Peles et al., 1997; Poliak et al., 1999, 2003). Antibodies against Gliomedin, $\mathrm{Na}^{+}$channels, Kv1.2, Kv2.1, TAG-1 and PSD-95 have been described previously (Dodd et al., 1988; Bekele-Arcuri et al., 1996; Rasband et al., 1999, 2002; Eshed et al., 2005). Anti-HA clone HA-7 was purchased from Sigma. Rat anti-Caspr serum was generated by immunizing rats with a GST fusion protein composed of the entire cytoplasmic domain of Caspr. For triple labeling, rabbit antibodies to PSD93 (see Fig. 1), PSD95 or TAG1 (see Fig. 2), Kv1.2 (see Fig. 3), were used together with a mouse monoclonal antibody to $\mathrm{Na}^{+}$ channels and a rat polyclonal antibody to Caspr (see Figs. 1, 2). Labeling of Caspr 2 transgenes was done using a mouse polyclonal serum against the extracellular domain of Caspr2, together with a rat polyclonal serum to Caspr and polyclonal rabbit antibodies to gliomedin (see Fig. 6), Kv1.2, TAG1 or PSD93 (see Fig. 7). Specificity and immunoreactivity of the antibodies to PSD-93, PSD-95, SAP97 and PSD-102 was determine using HEK-293 cells transfected with the relevant cDNAs, as well as by staining nerves isolated from mice lacking PSD-93, PSD-95, or both genes.

Surface labeling, immunoprecipitation and immunoblot analysis. Coimmunoprecipitation experiments were performed using brain membranes prepared from wild-type, Caspr $2^{-1-}, P S D-93^{-1-}, P S D-95^{-1-}$ or $P S D-$ $93^{-1-} / P S D-95^{-1-}$ animals. Whole brains were homogenized in a buffer containing 20 mM HEPES, pH 7.4, 0.32 м sucrose, 1 mM EGTA, 1.5 mM $\mathrm{MgSO}_{4} 10 \mu \mathrm{g} / \mathrm{ml}$ aprotinin and leupeptin, and $1 \mathrm{~mm}$ phenylmethyl sulfonyl fluoride. Nuclei and heavy cell debris were removed by low-speed centrifugation $(1000 \times g)$ for $10 \mathrm{~min}$, and the supernatant was subjected to high-speed centrifugation $(40,000 \times g)$ for $60 \mathrm{~min}$. Membrane solubilization, immunoprecipitation, and immunoblots were conducted as described previously (Poliak et al., 1999). Cell surface biotinylation of HEK-293 transfected cells was performed as described (Gollan et al., 2003).

Immunofluorescence. Sciatic nerves were dissected and immersed in Zamboni's fixative for $10 \mathrm{~min}$. In some cases, nerves were fixed in icecold $4 \%$ paraformaldehyde for $30 \mathrm{~min}$. After desheathing, nerves were teased on Super-Frost Plus slides, dried for $2 \mathrm{~h}$, and frozen at $-20^{\circ} \mathrm{C}$ until used. Preparation and staining of optic nerve sections have been previously described (Poliak et al., 1999). The preparations were postfixed/ permeabilized in methanol at $-20^{\circ} \mathrm{C}$ for $10 \mathrm{~min}$. Slides were washed and blocked for $1 \mathrm{~h}$ with blocking buffer (PBS containing 10\% normal goat serum, $0.1 \%$ Triton X-100, and $1 \%$ glycine). The samples were incubated overnight at $4^{\circ} \mathrm{C}$ with the different primary antibodies described above diluted in blocking solution. Slides were washed three times for $5 \mathrm{~min}$ in PBS and incubated for $1 \mathrm{~h}$ with secondary antibodies: anti mouse-Cy3 or biotinylated anti-rabbit (Jackson Immuno Research). The latter was washed in PBS and reacted with streptavidin-Alexa-488 (Invitrogen) for $45 \mathrm{~min}$ and was further processed as described previously (Poliak et al., 1999). Cos-7 cells seeded on glass slides were transfected using Lipofectamine plus reagent (Invitrogen). Forty-eight hours later, cells were washed with PBS and fixed in 4\% paraformaldehyde for $15 \mathrm{~min}$ at room temperature. After washing with PBS, the cells were incubated in blocking buffer either with or without $0.1 \%$ Triton X-100 for $30 \mathrm{~min}$ at ambient temperature. Primary antibodies were diluted in blocking buffer and incubated for $2 \mathrm{~h}$. Following three washes with PBS, slides were incubated with secondary antibodies for $45 \mathrm{~min}$ in DAPI-containing blocking buffer, and subsequently washed with PBS and mounted in elvanol. Images were acquired using Open Lab software (Improvision) with a cooled ORCA-ER camera (Hamamatsu) attached to a Nikon TE-1000 microscope.

Mass spectrometric analysis. Rat brain membrane lysates (Poliak et al., 2003) were mixed with GST-fusion proteins coupled to glutathione beads for $12 \mathrm{~h}$ at $4^{\circ} \mathrm{C}$. Beads were washed with a buffer containing $0.15 \%$ sucrose monolaurate and separated on $4-12 \%$ gradient gel. The proteins in the gel were reduced (10 mM dithiothreitol), modified with $40 \mathrm{~mm}$ iodoacetamide and trypsinized (modified trypsin; Promega) at a 1:100 enzyme-to-substrate ratio. The resulting tryptic peptides were resolved by reverse-phase chromatography on $0.075 \times 200 \mathrm{~mm}$ fused silica capillaries (J\&W) packed with Reprosil reversed phase material (Dr Maisch $\mathrm{GmbH})$. The peptides were eluted with linear 95 min gradients of $7-40 \%$ and $25 \mathrm{~min}$ at $95 \%$ acetonitrile with $0.1 \%$ formic acid in water at flow rates of $0.25 \mu \mathrm{l} / \mathrm{min}$. Mass spectrometry was performed by an ion-trap mass spectrometer (Orbitrap, Thermo) in a positive mode using repetitively full MS scan followed by collision induced dissociation of the seven most dominant ions selected from the first MS scan. The mass spectrometry data were clustered and analyzed using the Sequest software (ThermoFisher) and Pep-Miner (Beer et al., 2004) searching against the vertebrate part of the NR-NCBI database.

\section{Results}

\section{PSD-93 is a juxtaparanodal component}

The PSD-95 family of PDZ scaffold proteins is thought to regulate $\mathrm{K}^{+}$channel targeting and membrane anchoring (Lai and Jan, 2006). This subgroup of membrane-associated guanylate kinase (MAGUK) contains four members (PSD-95/SAP90, PSD-93/ 


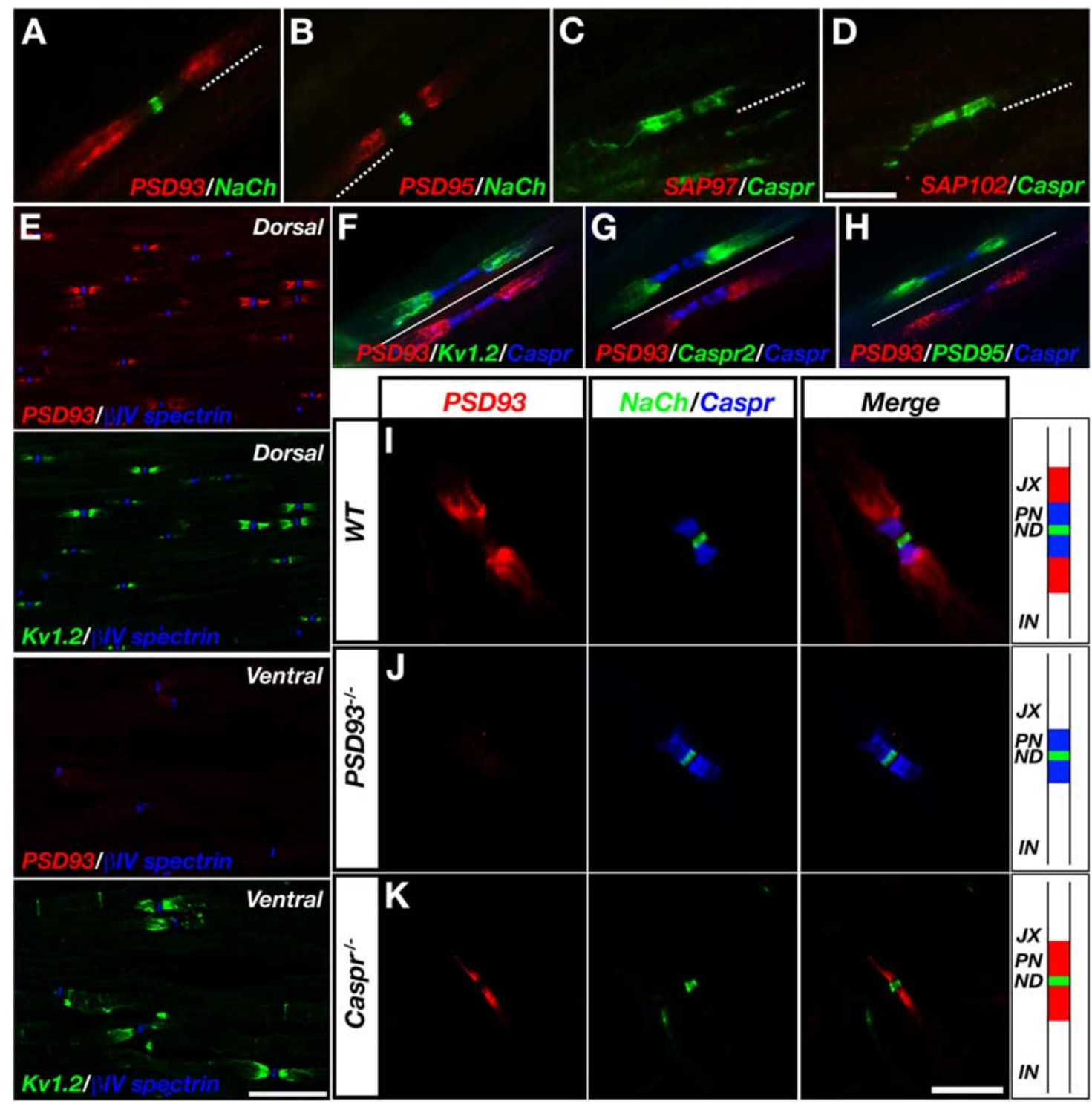

Figure 1. PSD-93 is found at the JXP of myelinated axons. $\boldsymbol{A}-\boldsymbol{D}$, Immunofluorescence labeling of teased adult rat sciatic nerves using antibodies to PSD-93 (A), PSD-95 (B), SAP97 (C), and SAP102 (D). The nodes of Ranvier $(\boldsymbol{A}, \boldsymbol{B})$ and paranodal junction $(\boldsymbol{C}, \boldsymbol{D})$ were labeled with antibodies to $\mathrm{Na}^{+}$channels (NaCh) and Caspr, respectively. $\boldsymbol{E}$, Immunolabeling of dorsal and ventral roots with antibodies to PSD-93, Kv1.2 and $\beta$ IV spectrin. Labeling for $\beta$ IV spectrin and PSD-93 is shown in the top, while the labeling for $\beta$ IV spectrin and Kv1.2 is shown in the bottom as indicated. Note that PSD-93 immunoreactivity is detected in all Kv1.2-positive JXP in the dorsal but not the ventral roots. $\boldsymbol{F}-\boldsymbol{H}$, At the juxtaparanodal region, PSD-93 colocalizes with Kv1.2 (F), Caspr2 (G) and PSD-95 (H). I-K, Teased sciatic nerves isolated from wild-type (WT), PSD-93 null (PSD-93 ${ }^{-/}-$), or Caspr null mice (Caspr ${ }^{-1}-$ ), were immunolabeled for PSD-93 (red), $\mathrm{Na}^{+}$channels (green) and Caspr (blue). The organization of the nodal environ is schematically shown on the right. JX, Juxtaparanodes; PN, paranodes; ND, nodes of Ranvier; IN, internodes. Scale bars, $10 \mu \mathrm{m}$.

chapsyn-110, SAP102 and SAP97) (Kim and Sheng, 2004), of which only PSD-95 was previously found at the JXP (Baba et al., 1999; Rasband et al., 2002). To determine the localization of the other PSD-MAGUKs along myelinated axons, we examined their distribution in rat sciatic nerve (Fig. 1). Double labeling, using antibodies to individual PSD-MAGUKs and to $\mathrm{Na}^{+}$channels (to mark the nodes), or Caspr (to mark the PNJ), revealed a clear accumulation of PSD-93 and PSD-95, but not of SAP97 or SAP-102 at the JXP (Fig. 1A-D) (32\% of nodes examined; $\mathrm{n}>300$ sites). To examine whether the partial appearance of PSD-93 in the JXP in sciatic nerve is due to its differential expression in a subset of axons, we immunolabeled dorsal and ventral roots (Fig. $1 E$ ). We found a profound difference between sensory and motor axons: in the dorsal root, $100 \%(n=300)$ of Kv1.2-labeled JXPs had PSD-93, while in the ventral root PSD-93 immunoreactivity was weaker and was detected in only 7\% $(n=312)$ of the Kv1.2 labeled JXP. At PSD-93-positive JXP, it was colocalized with Kv1.2, Caspr2 and PSD-95 (Fig. $1 F-H$ ). Strong PSD-93 immunolabeling was also detected at the JXP in sciatic nerve obtained from wildtype mice (Fig. 1I). Juxtaparanodal immunoreactivity of PSD-93 was never detected in sciatic nerves obtained from PSD-93-null mice ( $n>200$ nodes) (McGee et al., 2001), although in these nerves $\mathrm{Na}^{+}$channels and Caspr clustered normally at nodes and paranodes, respectively (Fig. $1 \mathrm{~J}$ ). Previous studies have shown that in the absence of an intact paranodal axoglial junction in the PNS, JXP proteins are found at the paranodes (Dupree et al., 1999; Bhat et al., 2001; Boyle et al., 2001; Poliak et al., 2001; Traka et al., 2002). In line with these observations, when detected, PSD-93 was always concentrated near the nodes of Ranvier ( $n=100$ sites) instead of the JXP in sciatic nerves obtained from $\mathrm{Caspr}^{-/-}$mice, which lacks the 
paranodal junction (Bhat et al., 2001; Gollan et al., 2003) (Fig. $1 \mathrm{~K}$ ). These results identify PSD-93 as a novel component of a subset of the JXPs.

\section{Juxtaparanodal accumulation of PSD-93 requires Caspr 2 and TAG-1}

Previous studies demonstrated that in the absence of Caspr2 or TAG-1, Kv1 channels disperse from the JXP and were located along the internodes (Poliak et al., 2003; Traka et al., 2003). To determine whether the accumulation of PSD-93 and PSD-95 at the JXP depends on the formation of the Caspr2/TAG-1 adhesion complex, we compared the distribution of these PSDMAGUKs in sciatic nerves isolated from wild-type mice to those isolated from mice lacking either Caspr2 or TAG1 genes. To enable the identification of the juxtaparanodal area in these mutants, we marked the adjacent PNJ using an antibody against Caspr. In support of our previous observations (Poliak et al., 2003), Caspr2 and TAG-1 were found at the JXP in wild type, but not in Caspr2 $2^{-/-}$or TAG1 $1^{-/-}$nerves (Fig. 2A-F). Immunofluorescence labeling, using specific antibodies to PSD-93 and PSD-95, revealed that while both proteins were detected at the JXP in wild-type nerves, they were absent from this site in nerves isolated from either Caspr $2^{-1-}$ or $T A G 1^{-/-}$animals (Fig. $2 G-L$ ). These results indicate that the accumulation of PSD-93 and PSD-95 at the JXP requires Caspr2 and TAG-1.

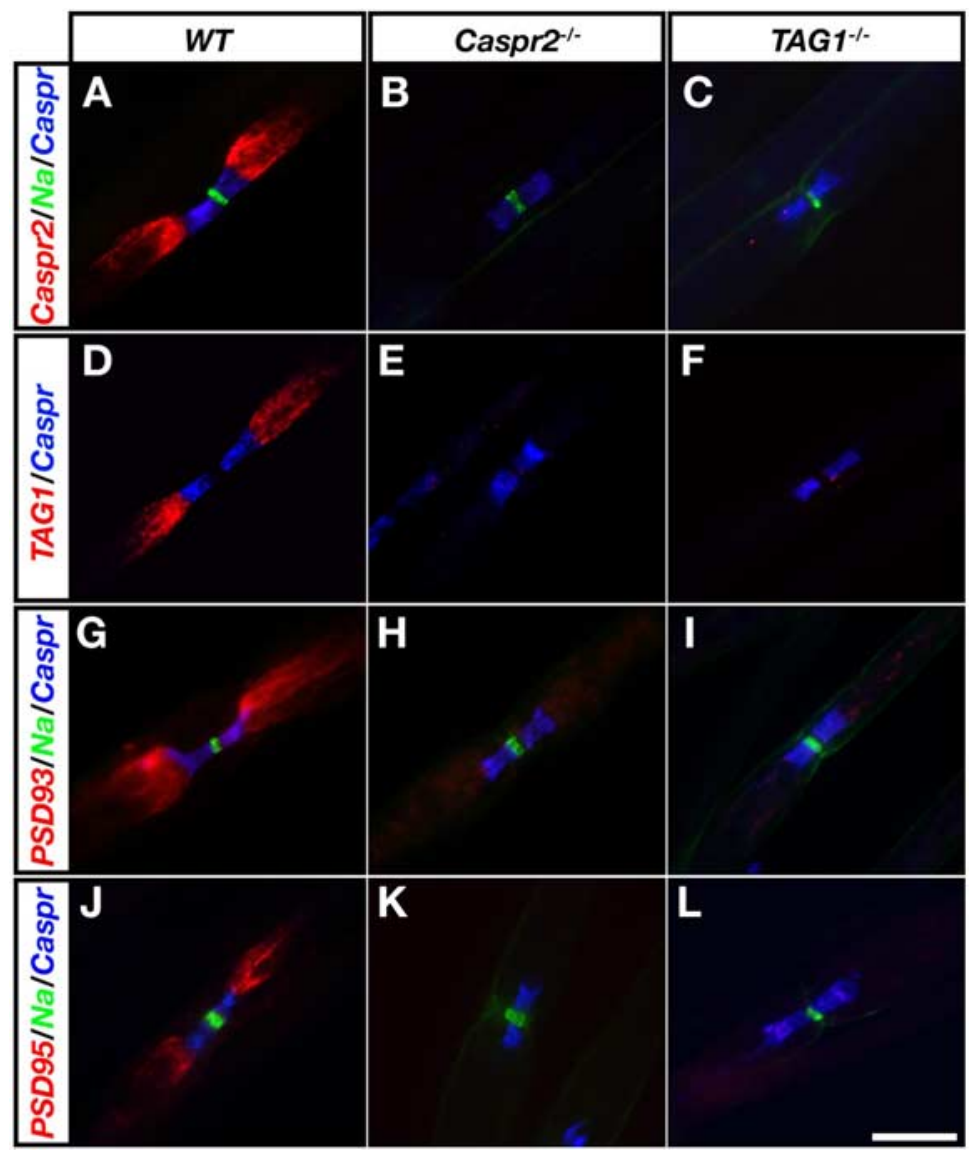

Figure 2. Juxtaparanodal accumulation of PSD-93 depends on Caspr2 and TAG-1. Immunofluorescence labeling of teased sciatic nerves isolated from wild-type (WT; $\boldsymbol{A}, \boldsymbol{D}, \mathbf{G}, \boldsymbol{J})$, Caspr2 null (Caspr2 $\left.{ }^{-/-} ; \boldsymbol{B}, \boldsymbol{E}, \boldsymbol{H}, \boldsymbol{K}\right)$, or TAG-1 null mice (TAG1 ${ }^{-/-} ; \boldsymbol{C}, \boldsymbol{F}$, $\boldsymbol{I}, \boldsymbol{L}$ ) using the following antibody combinations: $\boldsymbol{A}-\mathbf{C}$, Caspr2 (red), $\mathrm{Na}^{+}$channels (green) and (aspr (blue); $\boldsymbol{D}$-- $\boldsymbol{F}, \mathrm{TAG}-\mathbf{1}$ (red) and Caspr (blue); G--I, PSD-93 (red), $\mathrm{Na}^{+}$channels (green) and Caspr (blue); J-L, PSD-95 (red), $\mathrm{Na}^{+}$channels (green) and Caspr (blue). Scale bar, $10 \mu \mathrm{m}$.

\section{Kv1 channels colocalize and associate with Caspr2 in mice lacking PSD-93 and PSD-95}

To determine whether PSD-93 plays a role in the membrane clustering of Caspr2 and Kv1 channels at the JXP, we examined the distribution of Kv1.2 in sciatic and optic nerves isolated from wild-type and PSD-93 ${ }^{-1-}$ mice (McGee et al., 2001). As depicted in Figure 3 (wild type: $A, E$ and $P S D 93^{-/-}: B, F$ ), nerves isolated from both genotypes showed normal appearance of the node and its associated domains i.e., clustering of $\mathrm{Na}^{+}$channels at nodes, Caspr at paranodes and Kv1.2 and Caspr2 at the JXP. In line with our previous observations (Rasband et al., 2002), Kv1.2 and Caspr2 were located at the JXP in mice lacking PSD-95 (Fig. $3 C, G)$. As the two closely related MAGUKs colocalized at the JXP and might functionally compensate for each other, we generated mice lacking both PSD-93 and PSD-95. Concurring with a recent report (Elias et al., 2006), double PSD-93-/- $/ P S D-95^{-/-}$animals clearly showed an abnormal phenotype when compared with the single mutants or to their heterozygous littermate controls. They were smaller in size, exhibited wide-based gate and reduced locomotor activity, and usually died by 3 weeks of age (data not shown). Immunofluorescence labeling of teased sciatic nerves and frozen optic nerve sections obtained from the double PSD-93 ${ }^{-/-} / P S D-95^{-/-}$mutant mice showed that $\mathrm{Na}^{+}$channels were concentrated at the nodes, Caspr at the PNJ and Kv1.2 at the JXP in a manner that was indistinguishable from wild-type mice (Fig. 3D,H). Similar to the wild-type sciatic nerves, Kv1.2 was concentrated in $>80 \%$ of JXPs in mice lacking PSD93, PSD95, or both proteins ( $n=150$ nodal sites examined for each genotype). SAP-97 and SAP-102 were not detected in sciatic nerves of double PSD-93 ${ }^{-/-} / P S D-95^{-/-}$animals, indicating that there was no upregulation of other PSD-MAGUKs at the JXP (supplemental Fig. 1, available at www.jneurosci.org as supplemental material) These results demonstrate that the clustering of Kv1 channels at the JXP axolemma occurs in the absence of both PSD-93 and PSD-95. They further suggest that these two PSD-MAGUK proteins do not mediate the interaction between Kv1 channels and Caspr2. To directly test whether this is the case, we immunoprecipitated Kv1.2 from brain membrane lysates prepared from wild-type, single, or double PSD$93^{-/-} / P S D-95^{-/-}$mice, followed by immunoblot analysis with an antibody to Caspr2 (Fig. 3I). Antibodies to Kv2.1 and Caspr2 were used as negative and positive controls, respectively. As an additional control for specificity, brains isolated from Caspr $2^{-/-}$mice were also used. We found that Caspr 2 coimmunoprecipitated with Kv1.2, but not with Kv2.1, in brains isolated from all genotypes except from Caspr $2^{-1-}$ mice. This result conclusively demonstrates that neither PSD-93 nor PSD-95 is required for the interaction between Kv1 channels and Caspr2.

\section{Generation of transgenic mice expressing deletion mutants of} Caspr2 in neurons

The cytoplasmic domain of Caspr2 contains a PDZ domainbinding sequence (EWLI) at its carboxy terminus that could me- 

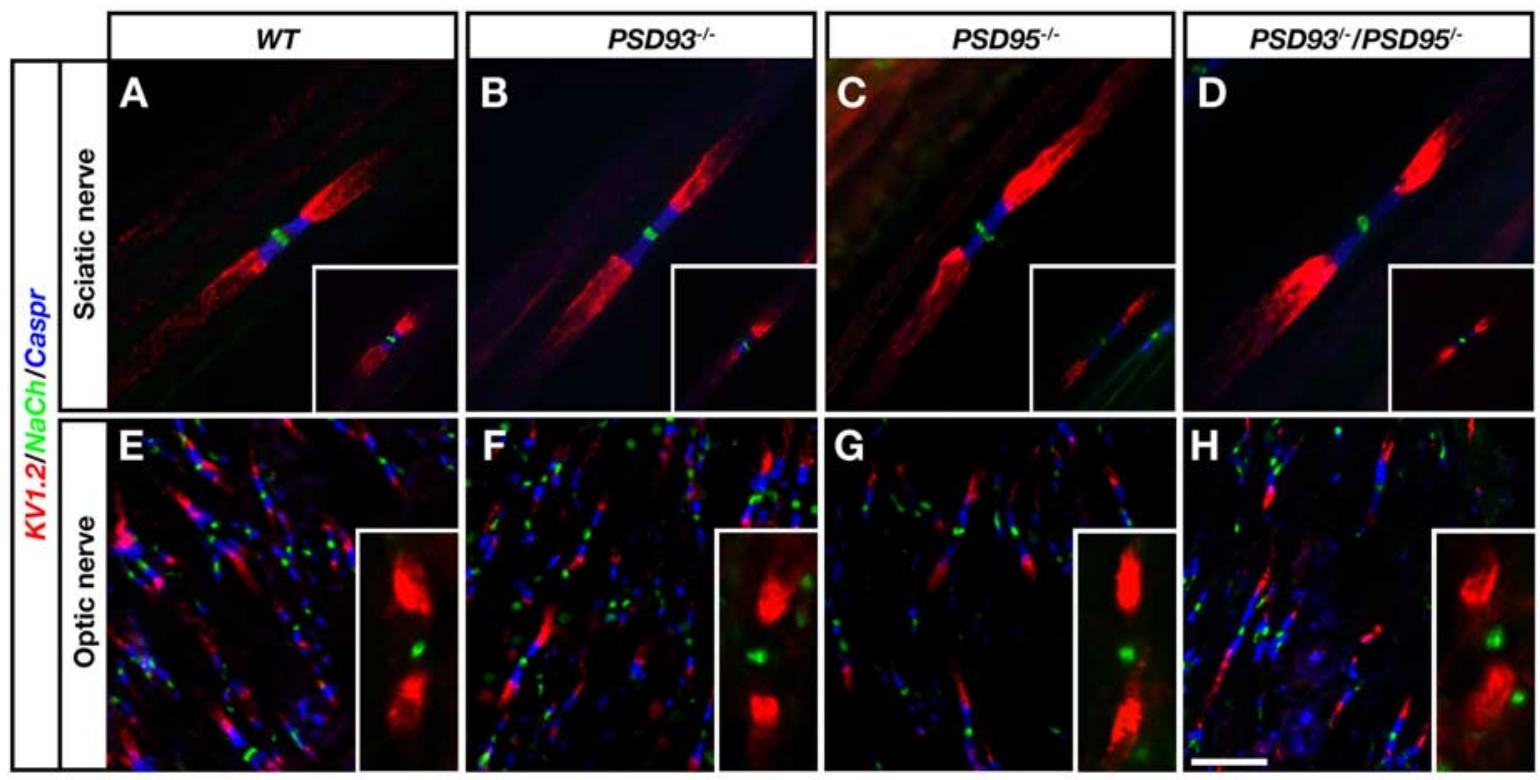

I

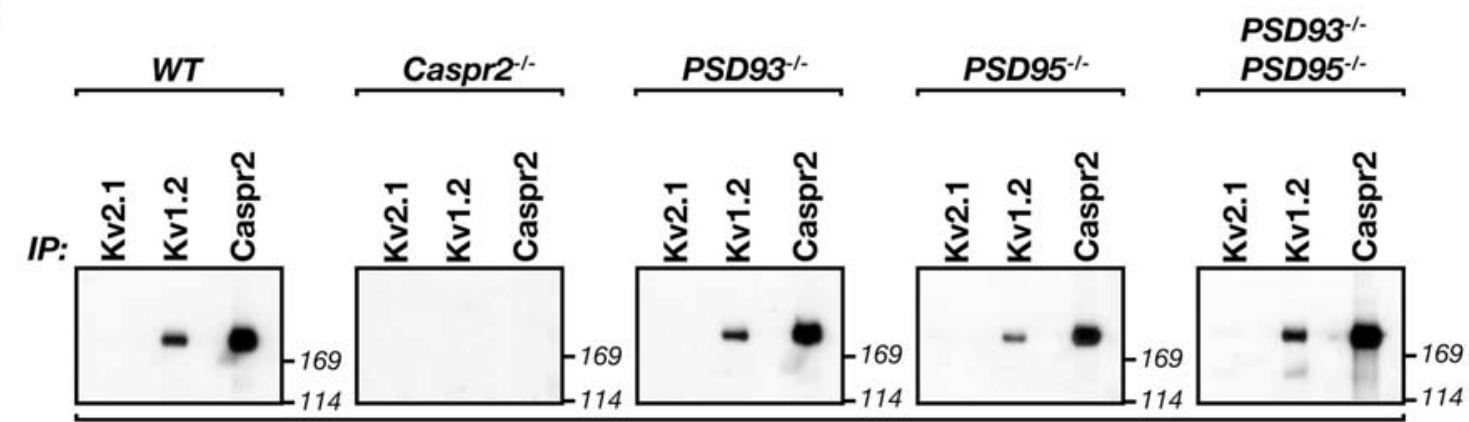

Blot Ab:

Caspr2

Figure 3. $\mathrm{K}^{+}$channels localized at the JXP and are associated with Caspr2 in mice lacking PSD-93 and PSD-95. Immunofluorescence labeling of teased sciatic nerves and optic nerve sections

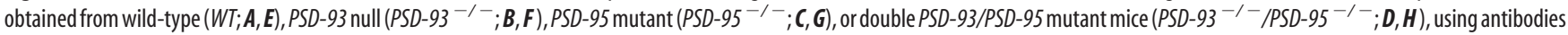
to Kv1.2 (red), $\mathrm{Na}^{+}$channels (green) and Caspr (blue). Insets in $\boldsymbol{A}--\mathbf{D}$ show staining for Caspr2 (red), $\mathrm{Na}^{+}$channels (green) and Caspr (blue). Insets in $\boldsymbol{E}-$ - $\boldsymbol{H}$ show high magnification staining of Kv1.2 (red) and $\mathrm{Na}^{+}$channels (green). Scale bar, $10 \mu \mathrm{m}$. I, Caspr2, Kv1.2, and Kv2.1 were immunoprecipitated from brain membrane lysates prepared from wild-type (WT), Caspr2 null (Caspr2 ${ }^{-{ }^{-}}$),

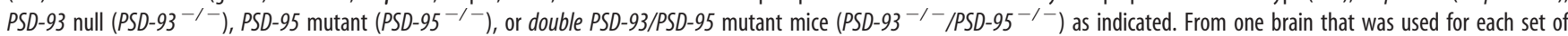
immunoprecipitation, $45 \%$ of the lysate was used for Kv1.2 and Kv2.1, whereas 10\% was used for Caspr2. Protein complexes were resolved on SDS-gel and blotted with an antibody to Caspr2. The location of molecular mass markers is shown on the left in $\mathrm{KDa}$.

diate its association with $\mathrm{K}^{+}$channels (Poliak et al., 1999; Spiegel et al., 2002). The observation that the two MAGUK scaffold proteins present at the JXP are dispensable for the clustering of $\mathrm{K}^{+}$ channels at this site, prompted us to directly examine whether the ability of Caspr2 to interact with PDZ domains is required for its association with Kv1 channels and the molecular assembly of the JXP. We therefore constructed a deletion mutant of Caspr2 lacking its PDZ-binding motif (C2dPDZ) (Fig. 4A), and tested whether it could restore JXP clustering of Kv1 channels when placed on the genetic background of Caspr2 null mice. As controls, we used a full-length Caspr2 cDNA (C2FL), as well as a deletion mutant lacking its entire cytoplasmic tail (C2dCT). All constructs also contained a HA tag at their extracellular domain (Fig. 5A). When transfected into HEK-293 cells, all three constructs were efficiently expressed on the cell surface, as was evident by surface biotinylation, followed by immunoprecipitation with an antibody to the HA-tag and blotting with streptavidinHRP (Fig. 4B). A similar conclusion was made based on the ability of an antibody directed to the extracellular region of Caspr2 to recognize all three constructs in intact, nonpermeabilized cells (Fig. 4C).
To express Caspr2 transgenes in CNS neurons and in longprojecting neurons in the PNS, they were placed under a Thy1.2 promoter (Caroni, 1997; Feng et al., 2000). Transgenic mice expressing each of the three transgenes were generated by pronuclear injection, and then crossed with mice lacking Caspr2, to obtain Caspr $2^{-/-} / F L$, Caspr2 ${ }^{-/-} / d P D Z$ and Caspr2 ${ }^{-/-} / d C T$ lines (collectively referred to here as Caspr2 $2^{-/-} / \mathrm{tg}$ ). PCR analysis of genomic tail DNA using primer sets specific for the transgenes or the endogenous Caspr2, confirmed that similar to Caspr2 nulls, the newly generated transgenic lines lacked the first coding exon of the Caspr2 gene (Fig. 5A). Transcripts of C2FL, C2dPDZ and $\mathrm{C} 2 \mathrm{dCT}$, but not of endogenous Caspr2, were detected in sensory neurons by RT-PCR using mRNA isolated from DRGs (Fig. 5B). We subsequently subjected brain membrane lysates prepared from the three Caspr $2^{-/-} / \mathrm{tg}$ lines to immunoprecipitation with antibodies that recognize the HA-tag or the cytoplasmic domain of Caspr2. Western blot analysis was then performed with antibodies to the HA-tag, the cytoplasmic domain or the extracellular domain of Caspr2. As depicted in Figure 5C, the expression of Caspr 2 transgenes could be detected using an HA tag antibody, as well as an antibody directed against the extracel- 
A

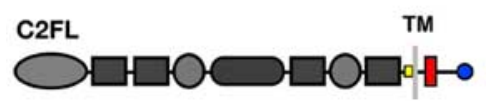

C2dPDZ
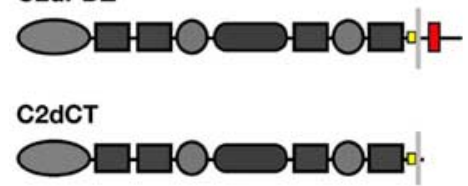

口GST ค PDZ-binding 4.1-binding
B

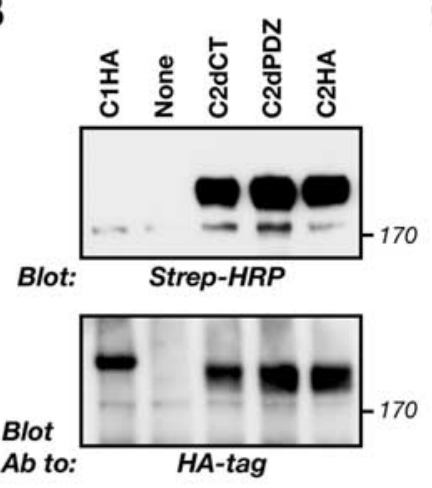

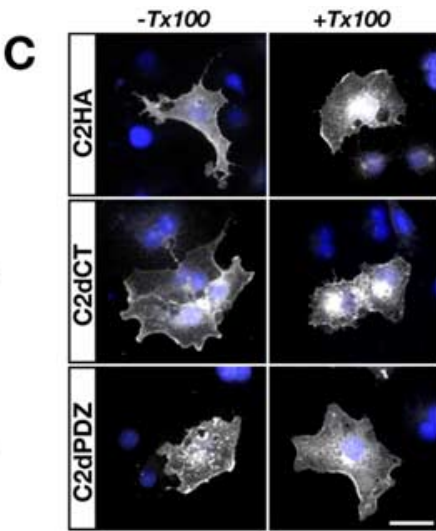

Figure 4. Characterization of Caspr 2 transgenes. A, Schematic presentation of the different Caspr 2 constructs used. The cytoplasmic domain of Caspr2 contains a 4.1 (red square) and a PDZ (blue circle)-binding sequences. (2FL encodes for a full-length HA-tagged (yellow square) Caspr2, whereas the (2dPDZ and C2dCT constructs encode for a Caspr2 lacking the PDZ-binding and the entire cytoplasmic region, respectively. B, Caspr2 transgenes reach the cell surface. Cell surface biotinylation was performed using HEK-293 cells (none), cells expressing an HA-tagged Caspr (C1HA), or HEK-293 cells expressing the indicated Caspr2 transgenes. Cell lysates were subjected to immunoprecipitation with an antibody to HA-tag followed by immunoblotting with the same antibody (bottom) or with streptavidin-HRP (top). The location of molecular mass markers is shown on the left in KDa. C1HA served as a control for a protein that does not reach the cell surface. C, COS-7 cells expressing the indicated transgenes, were labeled with an antibody to the extracellular domain of Caspr2 in either the absence ( - ) or the presence (+) of Triton X-100 (Tx100) as indicated. Cell nuclei are labeled with Dapi (Blue). Scale bar, $30 \mu \mathrm{m}$.

A

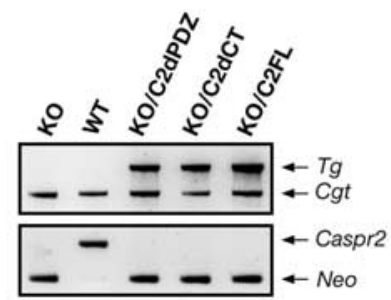

B

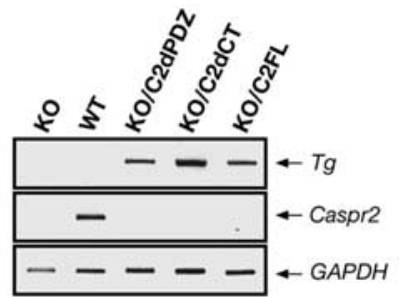

C
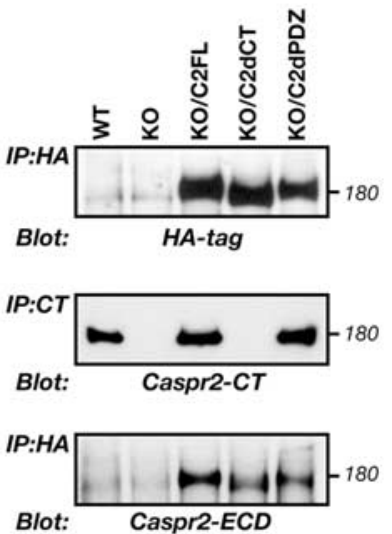

D

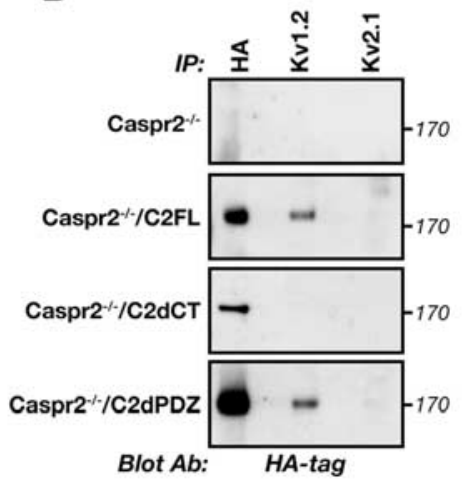

E
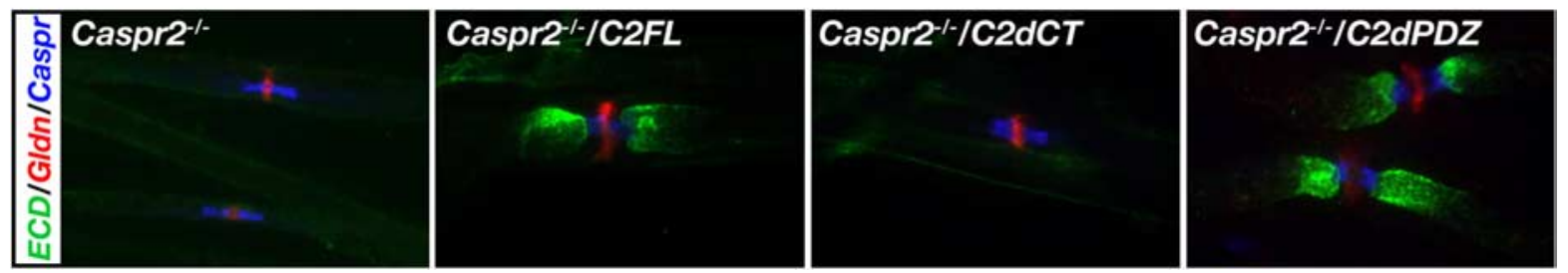

Figure 5. Caspr2FL and Caspr2dPDZ colocalize and associate with $\mathrm{K}^{+}$channels. $A$, Genomic PCR analysis. Tail DNA isolated from the animals indicated was used as a template for PCR using primer sets that recognize the transgene (tg), ceramide galactosyltransferase (Cgt), Caspr2 or neomycin (Neo). $\boldsymbol{B}$, Expression of transgenic transcripts in DRG neurons. mRNA isolated from DRGs from the animals indicated were used as a template for RT-PCR using primer sets that recognize the transgene ( $\mathrm{tg}$ ), Caspr2 or GAPDH as a control. C, Expression of Caspr2 transgenes. Brain lysates were prepared from wild-type mice (WT), mice lacking Caspr2 (K0), or the indicated Caspr2 transgenic expressed on the Caspr2 null background. Immunoprecipitation (IP) was performed using an antibody to HA-tag (HA) or to the cytoplasmic domain of Caspr2 (CT), followed by immunoblotting with antibodies to HA-tag, the cytoplasmic domain (Caspr2-CT) or the extracellular domain (Caspr2-ECD) of Caspr2 as indicated below each panel. D, Association of Caspr2 transgenes with $\mathrm{K}^{+}$channels. Brain membrane lysates prepared from the mice lines indicated were subjected to IP with antibodies to HA-tag (HA), Kv1.2 or Kv2.1, followed by immunoblotting with an antibody to HA-tag. E, Localization of Caspr2 transgenes in sciatic nerve. Teased sciatic nerve fibers isolated from the indicated mouse lines were immunolabeled using an antibody to gliomedin (Gldn; red) to label the nodes, Caspr (blue) to label the paranodal junction, and an antibody that recognizes the extracellular domain of Caspr2 (ECD; green). Scale bar, $10 \mu \mathrm{m}$.

lular domain, whereas an antibody against the intracellular region of Caspr2, only recognized C2FL and C2dPDZ but did not recognize $\mathrm{C} 2 \mathrm{dCT}$. In contrast to wild-type mice, no expression of the endogenous Caspr2 protein was detected in either Caspr2 ${ }^{-1-}$ or in the Caspr $2^{-I-} / \mathrm{tg}$ lines, further demonstrating that the transgenes were expressed on a Caspr 2 null background.
Rescue of the juxtaparanodal complex by Caspr2 lacking the PDZ-binding motif

To examine whether Caspr2 transgenes associate with Kv1 channels, we immunoprecipitated Kv1.2 from brain lysates prepared from Caspr2 $2^{-1-}$ and Caspr $2^{-/-} / \mathrm{tg}$ lines, and analyzed the precipitated protein complexes by Western blot using an antibody to 


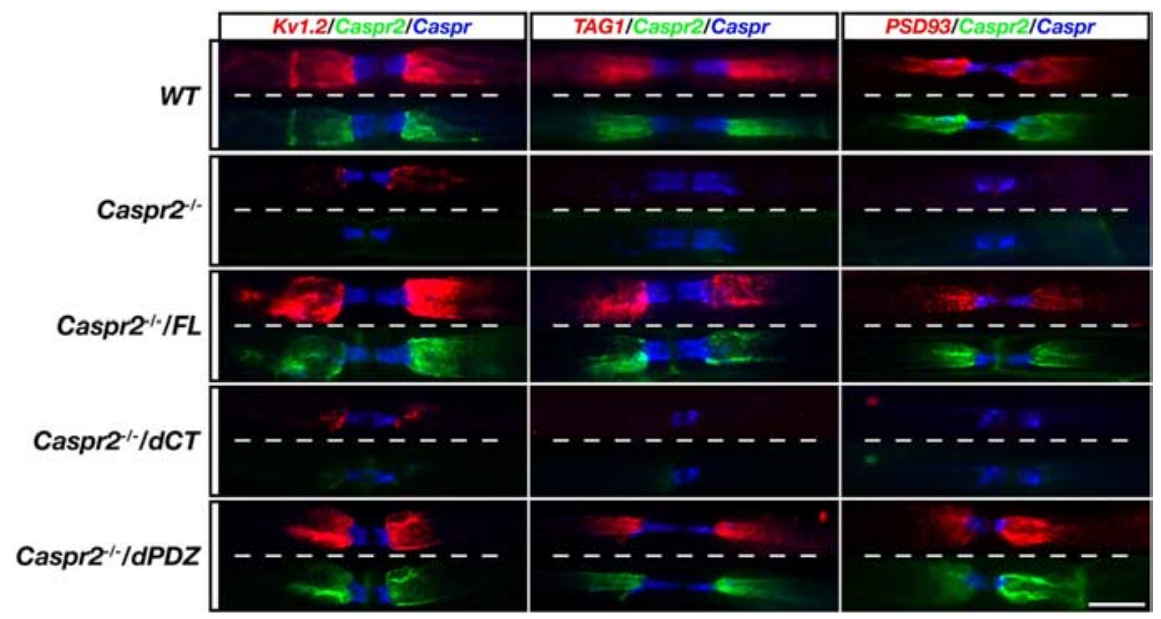

Figure 6. Rescue of the juxtaparanodal protein complex by Caspr2 lacking the PDZ-binding motif. Triple immunofluorescence labeling of teased sciatic nerves isolated from wild-type mice (WT), Caspr2 nulls (Caspr $2^{-1-}$ ), or Caspr2 nulls expressing the $F L$ (Caspr2 $\left.2^{-1-} / F L\right), d C T\left(\right.$ Caspr2 ${ }^{-1-} / d C T$ ), and dPDZ (Caspr2 ${ }^{-/-} / d P D Z$ ) transgenes, using antibodies to Caspr (blue), Caspr2-ECD (green), and Kv1.2 (reg; left column), TAG-1 (red; middle column), or PSD93 (red; right column). The red and blue channels are shown in the upper part, while the green and the blue channels are shown in the lower part of each panel. Note that Caspr2, Kv1.2 and TAG-1 are present at the JXP region in WT, Caspr2 ${ }^{-1-} / \mathrm{FL}$ and Caspr2 ${ }^{-1-} / \mathrm{dPDZ}$ nerves, but not in nerves isolated from Caspr2 $^{-1-}$ or Caspr2 $2^{-1-} / C T$. Scale bar, $10 \mu \mathrm{m}$.

the HA-tag (Fig. 5D). We found that the C2FL, as well as the Caspr2 mutant lacking its PDZ-binding sequence (C2dPDZ) coimmunoprecipitated with Kv1.2. We estimated that $<5 \%$ of the total Kv1.2 associated with C2FL and C2dPDZ, a similar ratio to the one reported for the association between the endogenous Caspr2 and this channel in wild-type animals (Poliak et al., 1999). In contrast, association between Kv1.2 and C2dCT was not detected, indicating that the cytoplasmic region of Caspr2 mediates its interaction with $\mathrm{Kvl}$ channels. In agreement with previous observations (Poliak et al., 1999), no association was detected between Caspr2 transgenes and Kv2.1.

We then examined the localization of Caspr2 transgenes along the sciatic nerve. Immunolabeling of teased fiber preparations using antibodies to $\mathrm{Na}$ channels, Caspr and Caspr2, revealed that C2FL and C2dPDZ were concentrated at the JXP (Fig. 5E). As expected, these transgenes were found only in some of the axons due to the variable activity of the Thyl promoter in a subset of DRG neurons (Feng et al., 2000; Gollan et al., 2002). The Caspr2 mutant lacking its entire cytoplasmic domain (C2dCT) was absent from the JXP although its transcript was detected in the DRG cell bodies (Fig. $5 A, E$ ). Furthermore, in contrast to Caspr2 ${ }^{-1-}$ nerves, weak immunoreactivity of C2dCT was detected along the internodes, indicating that it was transported to the axon. This conclusion was further supported by the observation that C2dCT was detected in sciatic nerve lysates by Western blots using an antibody to Caspr2 (data not shown).

Last, we examined whether the different Caspr2 transgenes could rescue the juxtaparanodal phenotype of Caspr $2^{-1-}$ mice. We immunolabeled teased sciatic nerves isolated from wild type, Caspr $2^{-/-}$, or the three transgenic lines using antibodies to Kv1.2, TAG-1 and PSD-93 (Fig. 6). We found that Kv1.2, TAG-1 and PSD-93 were clustered at the JXP in wild type, Caspr $2^{-/-} / F L$ and Caspr $2^{-/-} / \mathrm{dPDZ}$, but not in Caspr $2^{-/-}$or Caspr2 ${ }^{-/-} / \mathrm{dCT}$ mice. JXP clustering of Kv1.2, TAG-1 and PSD-93 was only detected at sites that also contained the Caspr2 transgene (i.e., C2FL and C2dPDZ). A rescue of JXP clustering was found in spinal cords isolated from the different genotypes (supplemental Fig. 2, available at www.jneurosci.org as supplemental material). To- gether, these results demonstrate that the intracellular region of Caspr2 is essential for its association with Kv1 channels, as well as for its targeting and assembly of the JXP complex. Surprisingly, channel association, axonal targeting and JXP formation do not require the PDZ-binding motif of Caspr2.

\section{Association of Caspr2 with scaffolding proteins requires its $\mathrm{PDZ}$ and \\ 4.1-binding motifs}

To search for scaffolding proteins that may be part of the Caspr $2 / \mathrm{K}^{+}$channel protein complex, we used a GST-fusion protein containing the cytoplasmic domain of Caspr2 to pull-down proteins capable of interacting with Caspr2 from rat brain lysate. Mass spectrometric analysis of the obtained complexes revealed that MUPP1, CASK, SAP97, and several members of the MPP family of MAGUKs were associated with Caspr2 (Fig. 7A). RT-PCR analysis of mRNA isolated from cultured DRG neurons or Schwann cells, demonstrated that MPP2, MPP3, MPP6 and to a lesser extent MPP7, are expressed by sensory neurons. To determine whether Caspr2 interacts with MPPs, as well as to identify the domains in Caspr2 that is required for such interaction, we examined whether GST-fusion proteins containing the cytoplasmic domain of Caspr2 (Fig. 7C) (GSTC2CT), a cytoplasmic domain lacking the PDZ-binding sequence (GST-C2dPDZ), or a cytoplasmic domain lacking its juxtamembrane protein-4.1-binding motif (GST-C2d4.1), could pull down myc-tagged MPPs from transfected HEK-293 cells. As depicted in Figure $7 D$, all the three MPPs examined, and the related protein CASK, but not SAP97, bound to the cytoplasmic domain of Caspr2 but not to the Caspr2 mutant lacking its carboxy terminus PDZ-binding sequence. However, in contrast to the interaction with MPP7 and CASK, which only required the PDZ-binding sequence of Caspr2, the association between Caspr2 and MPP2 or MPP6 was also dependent on the presence of its juxtamembrane protein 4.1-binding motif. These results suggest that high affinity interaction of MPP2 or MPP6 with Caspr2 may require simultaneous binding of protein 4.1, a manner analogous to the cooperative binding of MPP1/(p55) and protein 4.1R to glycophorin-C in erythrocytes (Nunomura et al., 2000). Furthermore, in contrast to GST-C2CT and GST-C2dPDZ, GST-C2d4.1 was unable to pull down Kv1.2 from rat brain lysate, indicating that the interaction of Caspr2 with 4.1 proteins may be required for its function in $\mathrm{K}^{+}$channel clustering and the assembly of the JXP (Fig. 7D, bottom).

\section{Discussion}

The precise distribution of receptors and ion channels in neurons is essential for the generation and propagation of action potentials and for synaptic transmission (Lai and Jan, 2006). In myelinated axons, $\mathrm{K}^{+}$channels with distinct biophysical characteristics are differentially located at specific membrane domains, namely the axon initial segment, the nodes of Ranvier and the JXP (Hedstrom and Rasband, 2006). The accumulation of Kv1 channels at the JXP requires a cell adhesion complex consisting of Caspr2 and TAG-1 (Poliak et al., 2003; Traka et al., 2003). In this study, we show that PSD-93/chapsyn-110 (Kim et al., 1996), a PSD-95 re- 


\section{A}

\begin{tabular}{|l|l|c|c|c|}
\hline$I D$ & Protein & Coverage & CT & GST \\
\hline 1858257 & MPP2 - (MAGUK p55 subfamily member 2/Dlgh2) & $40 \%$ & 15 & 0 \\
\hline 1343489 & MUPP1 - multiple PDZ domain protein & $\underline{37 \%}$ & 49 & 0 \\
\hline 1927340 & MPP6 - (MAGUK p55 subfamily member 6/Pals2/NAM1/p55T) & $\underline{24 \%}$ & 9 & 0 \\
\hline 1927339 & MPP5 - (MAGUK p55 subfamily member 5/Pals1) & $\underline{14 \%}$ & 8 & 0 \\
\hline 107231 & DLG1 - (SAP97 - Synapse-associated protein 97) & $\underline{12 \%}$ & 9 & 0 \\
\hline 1328354 & MPP3 - (MAGUK p55 subfamily member 3/DIgh3) & $\underline{8 \%}$ & 3 & 0 \\
\hline 1309489 & CASK - (mLin-2) & $4 \%$ & 3 & 0 \\
\hline
\end{tabular}
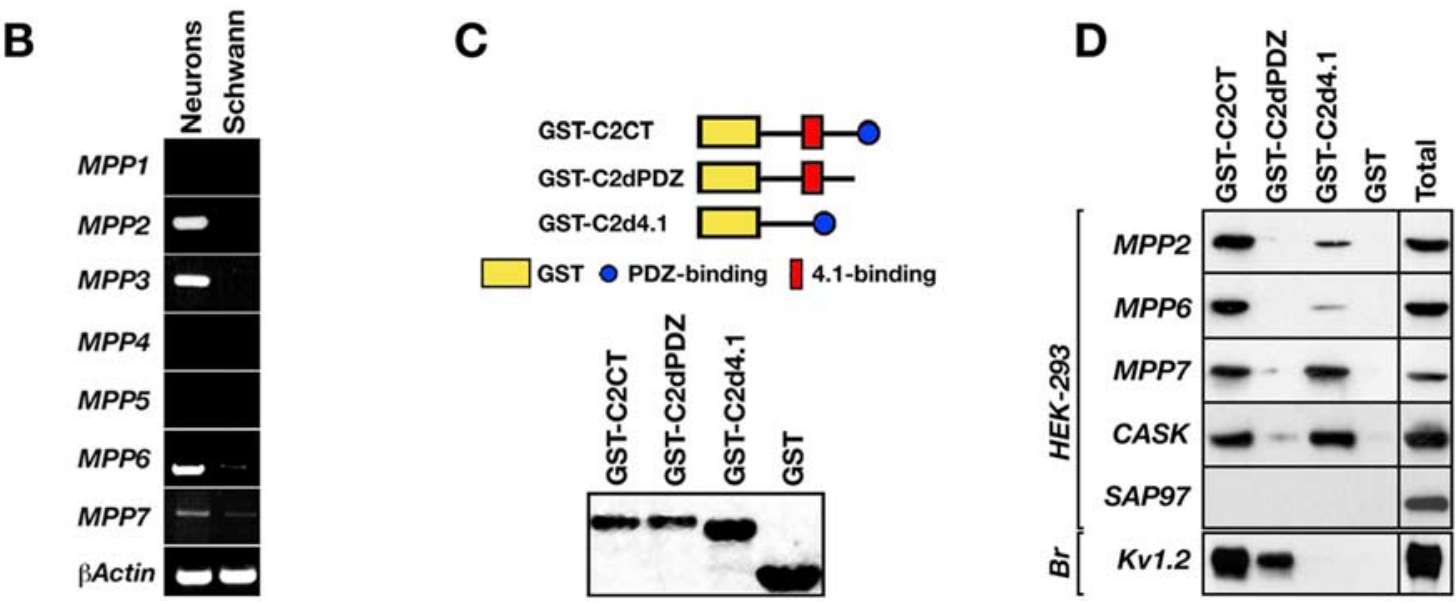

Figure 7. Association of Caspr2 cytoplasmic domain with MPPs requires its protein 4.1-binding sequence. A, Proteomic identification of scaffolding proteins associated with the cytoplasmic domain of Caspr2. ID, GenBank identification; Coverage, percentage of the protein sequence covered by the peptides identified; CT and GST, number of times each protein was identified using the cytoplasmic domain of Caspr2 (CT) or with GST control. B, Expression of MPPs in DRG neurons and Schwann cells. RT-PCR analysis of mRNA isolated from cultured DRG neurons and Schwann cells using specific primers for the different MPPs and $\beta$-actin as control. C, Caspr2 fusion proteins used for pull-down experiments. A schematic representation of the different constructs along with coomassie brilliant blue staining of an SDS gel containing the isolated proteins. D, Association of Caspr2 with MPP2, MPP6 and Kv1.2 require its PDZ- and protein 4.1 binding motif. GST-fusion proteins containing the cytoplasmic domain of Caspr2 (GST-C2CT), a cytoplasmic domain lacking the PDZ-binding sequence (GST-C2dPDZ), or a cytoplasmic domain lacking its juxtamembrane protein-4.1-binding motif (GST-C2d4.1) were used to pulldown myc-tagged proteins from transfected HEK-293 cells, or Kv1.2 from rat brain as indicated. Protein complexes were separated on SDS-gels and immunoblotted with an antibody to Myc-tag or to Kv1.2.

lated MAGUK is concentrated in a subset of the JXP in both the PNS and CNS. We found that in the absence of Caspr2 or TAG-1, PSD-93 no longer accumulates at the JXP, indicating that it is part of the juxtaparanodal complex. Consistently, PSD-93 is abnormally located with other JXP proteins adjacent to the nodes in peripheral axons of Caspr null mice, which lack a normal paranodal junction. To directly examine whether PSD-93 and PSD-95 function similarly in the clustering of Kv1 channels at the JXP, we have analyzed the nodal environ in sciatic and optic nerves isolated from mice lacking both of these genes. We found that despite the absence of PSD-95 and PSD-93, Kv1 channels, as well as Caspr 2 and Tag- 1 were normally localized at the JXP. It should be noted that there was no increase in the expression of other MAGUKs such as SAP97 and SAP102, both of which could functionally compensate for the loss of PSD-93 and PSD-95 (Elias et al., 2006). Hence, our results indicate that in contrast to glutamatergic synapses, PSD MAGUKs are not required for the targeting and clustering of Kv1 channels at the JXP.

We have previously found that Caspr2 coimmunoprecipitated with Kv1.1, Kv1.2 and their $\mathrm{Kv} \beta$ subunit from rat brain, indicating that it is found in a protein complex containing these channels (Poliak et al., 1999). This complex was also isolated from brain membrane lysates using a short peptide from the cytoplasmic domain of Caspr2 or Kv1.2 that contained their carboxy-terminal PDZ domain-binding sequence. In contrast, the association between Caspr2 and Kv1 channels was not observed when these proteins were coexpressed in transfected cells, suggesting that the formation of the juxtaparanodal Caspr2/Kv channels complex is likely to be mediated by a PDZ domaincontaining linker protein (Poliak and Peles, 2003; Schafer and Rasband, 2006). Notably, although the accumulation of PSD-93 and PSD-95 at the JXP depends on the presence of the Caspr2/ TAG-1 adhesion complex, Caspr2 was still associated with Kv1 channels in mice lacking both MAGUKs, indicating that they are not solely mediating this interaction. To further determine the requirement of $\mathrm{PDZ}$ containing proteins in the function of Caspr2 at the JXP, we used transgenic mutant forms of Caspr2 expressed on the background of Caspr2 null mice. While a fulllength Caspr2 transgene was localized at the JXP, a Caspr2 mutant lacking its cytoplasmic domain (Caspr2dCT) was distributed along the internodes, indicating that the intracellular region of Caspr2 is required for its targeting to the JXP. Caspr2dCT also did not associate with Kv1 channels, indicating that the interaction between Caspr2 and these channels is mediated by sequences present in its cytoplasmic domain. Surprisingly, a Caspr2 mutant lacking its PDZ domain-binding sequence (Caspr2dPDZ) was properly clustered at the JXP. Similar to the full-length Caspr2, Caspr2dPDZ transgene was associated with Kvl channels and induced their clustering at the JXP. These results demonstrate that although the association between Caspr2 and Kv1 channels requires its cytoplasmic domain, it is mediated by sequences other than the carboxy-terminal PDZ-binding motif. This conclusion is further supported by the observation that a GST-fusion protein containing the cytoplasmic domain of Caspr2 lacking its 
4.1-binding sequence was unable to pull down Kv1.2 from rat brain homogenate.

Using a proteomic approach, we identified several scaffolding proteins that interact directly (i.e., MPPs and CASK), or indirectly (i.e., SAP97), with the cytoplasmic domain of Caspr2. Of particular interest is the identification of members of the MPPs, a family of MAGUKs that contain several protein-protein interaction domains (PDZ, L27, SH3, guanylate kinase, and a protein 4.1-binding motif) (Kamberov et al., 2000; Wu et al., 2007), which enable these proteins to form large protein complexes containing synaptic MAGUKs (Karnak et al., 2002; Jing-Ping et al., 2005), and ion channels (Leonoudakis et al., 2004). Furthermore, MPP2 and MPP6 belong to a subgroup of the MPPs that also contain Varicose, a scaffolding protein that interacts with Neurexin IV, the Drosophila homolog of Caspr and Caspr2 (Wu et al., 2007). We showed that the association of Caspr2 with MPP2 and MPP6 requires both its PDZ- and 4.1-binding sequence. In contrast, we found that the ability of the cytoplasmic domain of Caspr2 to pull-down Kv1 channel was dependent on the presence of its 4.1-binding and not on its carboxy-terminal sequence that binds PDZ domains. The latter result is consistent with the rescue experiments in the Caspr2 $2^{-1-}$ mice, which also showed that the PDZ-binding sequence of Caspr2 is not required for Kv1.2 association or clustering. Thus, these results indicate that protein 4.1, or a related protein plays an important role in the association of Caspr2 with Kv1 channels and their clustering at the JXP. What could be the role of MPPS in myelinated axons? The requirement of both the 4.1 and PDZ-binding sequences in Caspr2 for its association with MPP2 and MPP6 may suggest that high affinity interaction between these MAGUKs and Caspr2 depend on the formation of a ternary complex with protein 4.1. Such cooperative binding was demonstrated for MPP1 (p55) and protein 4.1R to the cytoplasmic domain of glycophorin C, which bears high sequence similarity with Caspr2 (Nunomura et al., 2000). By analogy, the binding of protein 4.1 to Caspr2 would allow the recruitment of MAGUK scaffolds even in the absence of direct interaction between the carboxy-terminal tail of Caspr2 and PDZ domains. This possibility is supported by the observation that MPP proteins contain a specific binding sequence for 4.1 proteins upstream from their PDZ domain (Kamberov et al., 2000). In myelinated axons, a likely candidate to mediate such a cooperative interaction is protein $4.1 \mathrm{~B}$, a cytoskeletal linker that interacts with Caspr proteins and is found at the PNJ and JXP (Ohara et al., 2000; Poliak et al., 2001; Denisenko-Nehrbass et al., 2003). Future studies using specific antibodies to MPPs will be required to determine whether these MAGUKs cooperate with protein $4.1 \mathrm{~B}$ in the assembly of the Caspr $2 / \mathrm{K}^{+}$channels complex at the JXP.

Recent data revealed that the molecular composition of nodes and JXP are remarkably similar to that of the AIS (Hedstrom and Rasband, 2006). The AIS is enriched in nodal Nav and KCNQ2/3 channels that are localized with adhesion molecules such as neurofascin and the cytoskeletal adaptor proteins ankyrin $\mathrm{G}$ (ankG) and $\beta I V$ spectrin. The AIS also contain several JXP components including, Kv1 channels (Inda et al., 2006; Kuba et al., 2006; Kole et al., 2007; Van Wart et al., 2007) and Caspr2 (Inda et al., 2006). However, despite this molecular similarity, there are fundamental differences in the mechanisms that control ion channel distribution at the nodes of Ranvier and the AIS. These differences result from the strict requirement of glial contact for nodal clustering (Poliak and Peles, 2003), compared with the role of intrinsic axonal factors necessary for AIS formation (Hedstrom and Rasband, 2006). For example, while clustering of Na channels at nodes requires neurofascin (Sherman et al., 2005), the localiza- tion of these channels, as well as of $\beta$ IV spectrin at the AIS does not require neurofascin and is strictly dependent on ankG (Garrido et al., 2003; Pan et al., 2006; Dzhashiashvili et al., 2007; Hedstrom et al., 2007; Yang et al., 2007). At the JXP, clustering of Kv1 channels requires axon-glia interaction mediated by the Caspr2/TAG-1 adhesion complex, but not PSD MAGUKs. In contrast, we recently showed that clustering of Kv1 channels at the AIS depends on the presence of PSD-93 but not on Caspr2 (Ogawa et al., 2008). Together, these results demonstrate that despite similar protein components, two distinct mechanisms are responsible for the molecular assembly of the JXP and the AIS.

\section{References}

Baba H, Akita H, Ishibashi T, Inoue Y, Nakahira K, Ikenaka K (1999) Completion of myelin compaction, but not the attachment of oligodendroglial processes triggers $\mathrm{K}(+)$ channel clustering. J Neurosci Res 58:752-764.

Beer I, Barnea E, Ziv T, Admon A (2004) Improving large-scale proteomics by clustering of mass spectrometry data. Proteomics 4:950-960.

Bekele-Arcuri Z, Matos MF, Manganas L, Strassle BW, Monaghan MM, Rhodes KJ, Trimmer JS (1996) Generation and characterization of subtype-specific monoclonal antibodies to $\mathrm{K}^{+}$channel alpha- and betasubunit polypeptides. Neuropharmacology 35:851-865.

Berghs S, Aggujaro D, Dirkx R Jr, Maksimova E, Stabach P, Hermel JM, Zhang JP, Philbrick W, Slepnev V, Ort T, Solimena M (2000) betaIV spectrin, a new spectrin localized at axon initial segments and nodes of ranvier in the central and peripheral nervous system. J Cell Biol 151:985-1002.

Bhat MA, Rios JC, Lu Y, Garcia-Fresco GP, Ching W, St Martin M, Li J, Einheber S, Chesler M, Rosenbluth J, Salzer JL, Bellen HJ (2001) Axonglia interactions and the domain organization of myelinated axons requires Neurexin IV/Caspr/Paranodin. Neuron 30:369-383.

Boyle ME, Berglund EO, Murai KK, Weber L, Peles E, Ranscht B (2001) Contactin orchestrates assembly of the septate-like junctions at the paranode in myelinated peripheral nerve. Neuron 30:385-397.

Caroni P (1997) Overexpression of growth-associated proteins in the neurons of adult transgenic mice. J Neurosci Methods 71:3-9.

Davis JQ, Lambert S, Bennett V (1996) Molecular composition of the node of Ranvier: identification of ankyrin-binding cell adhesion molecules neurofascin (mucin+/third FNIII domain-) and NrCAM at nodal axon segments. J Cell Biol 135:1355-1367.

Denisenko-Nehrbass N, Oguievetskaia K, Goutebroze L, Galvez T, Yamakawa H, Ohara O, Carnaud M, Girault JA (2003) Protein 4.1B associates with both Caspr/paranodin and Caspr2 at paranodes and juxtaparanodes of myelinated fibres. Eur J Neurosci 17:411-416.

Dodd J, Morton SB, Karagogeos D, Yamamoto M, Jessell TM (1988) Spatial regulation of axonal glycoprotein expression on subsets of embryonic spinal neurons. Neuron 1:105-116.

Dupree JL, Girault JA, Popko B (1999) Axo-glial interactions regulate the localization of axonal paranodal proteins. J Cell Biol 147:1145-1152.

Dzhashiashvili Y, Zhang Y, Galinska J, Lam I, Grumet M, Salzer JL (2007) Nodes of Ranvier and axon initial segments are ankyrin G-dependent domains that assemble by distinct mechanisms. J Cell Biol 177:857-870.

Elias GM, Funke L, Stein V, Grant SG, Bredt DS, Nicoll RA (2006) Synapsespecific and developmentally regulated targeting of AMPA receptors by a family of MAGUK scaffolding proteins. Neuron 52:307-320.

Eshed Y, Feinberg K, Poliak S, Sabanay H, Sarig-Nadir O, Spiegel I, Bermingham JR Jr, Peles E (2005) Gliomedin mediates Schwann cell-axon interaction and the molecular assembly of the nodes of Ranvier. Neuron 47:215-229.

Feng G, Mellor RH, Bernstein M, Keller-Peck C, Nguyen QT, Wallace M, Nerbonne JM, Lichtman JW, Sanes JR (2000) Imaging neuronal subsets in transgenic mice expressing multiple spectral variants of GFP. Neuron 28:41-51.

Garrido JJ, Giraud P, Carlier E, Fernandes F, Moussif A, Fache MP, Debanne D, Dargent B (2003) A targeting motif involved in sodium channel clustering at the axonal initial segment. Science 300:2091-2094.

Gollan L, Sabanay H, Poliak S, Berglund EO, Ranscht B, Peles E (2002) Retention of a cell adhesion complex at the paranodal junction requires the cytoplasmic region of Caspr. J Cell Biol 157:1247-1256.

Gollan L, Salomon D, Salzer JL, Peles E (2003) Caspr regulates the process- 
ing of contactin and inhibits its binding to neurofascin. J Cell Biol 163:1213-1218.

Hedstrom KL, Rasband MN (2006) Intrinsic and extrinsic determinants of ion channel localization in neurons. J Neurochem 98:1345-1352.

Hedstrom KL, Xu X, Ogawa Y, Frischknecht R, Seidenbecher CI, Shrager P, Rasband MN (2007) Neurofascin assembles a specialized extracellular matrix at the axon initial segment. J Cell Biol 178:875-886.

Inda MC, DeFelipe J, Muñoz A (2006) Voltage-gated ion channels in the axon initial segment of human cortical pyramidal cells and their relationship with chandelier cells. Proc Natl Acad Sci U S A 103:2920-2925.

Jing-Ping Z, Tian QB, Sakagami H, Kondo H, Endo S, Suzuki T (2005) p55 protein is a member of PSD scaffold proteins in the rat brain and interacts with various PSD proteins. Brain Res Mol Brain Res 135:204-216.

Kamberov E, Makarova O, Roh M, Liu A, Karnak D, Straight S, Margolis B (2000) Molecular cloning and characterization of Pals, proteins associated with mLin-7. J Biol Chem 275:11425-11431.

Karnak D, Lee S, Margolis B (2002) Identification of multiple binding partners for the amino-terminal domain of synapse-associated protein 97. J Biol Chem 277:46730-46735.

Kim E, Sheng M (2004) PDZ domain proteins of synapses. Nat Rev Neurosci 5:771-781.

Kim E, Niethammer M, Rothschild A, Jan YN, Sheng M (1995) Clustering of Shaker-type $\mathrm{K}^{+}$channels by interaction with a family of membraneassociated guanylate kinases. Nature 378:85-88.

Kim E, Cho KO, Rothschild A, Sheng M (1996) Heteromultimerization and NMDA receptor-clustering activity of Chapsyn-110, a member of the PSD-95 family of proteins. Neuron 17:103-113.

Kole MH, Letzkus JJ, Stuart GJ (2007) Axon initial segment kvl channels control axonal action potential waveform and synaptic efficacy. Neuron 55:633-647.

Kordeli E, Lambert S, Bennett V (1995) AnkyrinG. A new ankyrin gene with neural-specific isoforms localized at the axonal initial segment and node of Ranvier. J Biol Chem 270:2352-2359.

Kuba H, Ishii TM, Ohmori H (2006) Axonal site of spike initiation enhances auditory coincidence detection. Nature 444:1069-1072.

Lai HC, Jan LY (2006) The distribution and targeting of neuronal voltagegated ion channels. Nat Rev Neurosci 7:548-562.

Leonoudakis D, Conti LR, Anderson S, Radeke CM, McGuire LM, Adams ME, Froehner SC, Yates JR 3rd, Vandenberg CA (2004) Protein trafficking and anchoring complexes revealed by proteomic analysis of inward rectifier potassium channel (Kir2.x)-associated proteins. J Biol Chem 279:22331-22346.

McGee AW, Topinka JR, Hashimoto K, Petralia RS, Kakizawa S, Kauer FW, Aguilera-Moreno A, Wenthold RJ, Kano M, Bredt DS, Kauer F (2001) PSD-93 knock-out mice reveal that neuronal MAGUKs are not required for development or function of parallel fiber synapses in cerebellum. J Neurosci 21:3085-3091.

Migaud M, Charlesworth P, Dempster M, Webster LC, Watabe AM, Makhinson M, He Y, Ramsay MF, Morris RG, Morrison JH, O’Dell TJ, Grant SG (1998) Enhanced long-term potentiation and impaired learning in mice with mutant postsynaptic density-95 protein. Nature 396:433-439.

Nunomura W, Takakuwa Y, Parra M, Conboy J, Mohandas N (2000) Regulation of protein $4.1 \mathrm{R}, \mathrm{p} 55$, and glycophorin $\mathrm{C}$ ternary complex in human erythrocyte membrane. J Biol Chem 275:24540-24546.

Ogawa Y, Horresh I, Trimmer JS, Bredt DS, Peles E, Rasband MN (2008) Postsynaptic density-93 clusters Kv1 channels at axon initial segments independently of Caspr2. J Neurosci 28:5731-5739.

Ohara R, Yamakawa H, Nakayama M, Ohara O (2000) Type II brain 4.1 (4.1B/KIAA0987), a member of the protein 4.1 family, is localized to neuronal paranodes. Brain Res Mol Brain Res 85:41-52.

Pan Z, Kao T, Horvath Z, Lemos J, Sul JY, Cranstoun SD, Bennett V, Scherer SS, Cooper EC (2006) A common ankyrin-G-based mechanism retains KCNQ and NaV channels at electrically active domains of the axon. J Neurosci 26:2599-2613.
Peles E, Nativ M, Lustig M, Grumet M, Schilling J, Martinez R, Plowman GD, Schlessinger J (1997) Identification of a novel contactin-associated transmembrane receptor with multiple domains implicated in proteinprotein interactions. EMBO J 16:978-988.

Poliak S, Peles E (2003) The local differentiation of myelinated axons at nodes of Ranvier. Nat Rev Neurosci 4:968-980.

Poliak S, Gollan L, Martinez R, Custer A, Einheber S, Salzer JL, Trimmer JS, Shrager P, Peles E (1999) Caspr2, a new member of the neurexin superfamily, is localized at the juxtaparanodes of myelinated axons and associates with $\mathrm{K}^{+}$channels. Neuron 24:1037-1047.

Poliak S, Gollan L, Salomon D, Berglund EO, Ohara R, Ranscht B, Peles E (2001) Localization of Caspr2 in myelinated nerves depends on axon-glia interactions and the generation of barriers along the axon. J Neurosci 21:7568-7575.

Poliak S, Salomon D, Elhanany H, Sabanay H, Kiernan B, Pevny L, Stewart CL, Xu X, Chiu SY, Shrager P, Furley AJ, Peles E (2003) Juxtaparanodal clustering of Shaker-like $\mathrm{K}^{+}$channels in myelinated axons depends on Caspr2 and TAG-1. J Cell Biol 162:1149-1160.

Rasband MN, Trimmer JS, Peles E, Levinson SR, Shrager P (1999) K ${ }^{+}$channel distribution and clustering in developing and hypomyelinated axons of the optic nerve. J Neurocytol 28:319-331.

Rasband MN, Park EW, Zhen D, Arbuckle MI, Poliak S, Peles E, Grant SG, Trimmer JS (2002) Clustering of neuronal potassium channels is independent of their interaction with PSD-95. J Cell Biol 159:663-672.

Salzer JL (2003) Polarized domains of myelinated axons. Neuron 40:297-318.

Schafer DP, Rasband MN (2006) Glial regulation of the axonal membrane at nodes of Ranvier. Curr Opin Neurobiol 16:508-514.

Sherman DL, Tait S, Melrose S, Johnson R, Zonta B, Court FA, Macklin WB, Meek S, Smith AJ, Cottrell DF, Brophy PJ (2005) Neurofascins are required to establish axonal domains for saltatory conduction. Neuron 48:737-742.

Spiegel I, Salomon D, Erne B, Schaeren-Wiemers N, Peles E (2002) Caspr3 and caspr4, two novel members of the caspr family are expressed in the nervous system and interact with PDZ domains. Mol Cell Neurosci 20:283-297.

Stucke VM, Timmerman E, Vandekerckhove J, Gevaert K, Hall A (2007) The MAGUK protein MPP7 binds to the polarity protein hDlg1 and facilitates epithelial tight junction formation. Mol Biol Cell 18:1744-1755.

Traka M, Dupree JL, Popko B, Karagogeos D (2002) The neuronal adhesion protein TAG-1 is expressed by Schwann cells and oligodendrocytes and is localized to the juxtaparanodal region of myelinated fibers. J Neurosci 22:3016-3024.

Traka M, Goutebroze L, Denisenko N, Bessa M, Nifli A, Havaki S, Iwakura Y, Fukamauchi F, Watanabe K, Soliven B, Girault JA, Karagogeos D (2003) Association of TAG-1 with Caspr2 is essential for the molecular organization of juxtaparanodal regions of myelinated fibers. J Cell Biol 162:1161-1172.

Van Wart A, Trimmer JS, Matthews G (2007) Polarized distribution of ion channels within microdomains of the axon initial segment. J Comp Neurol 500:339-352.

Wang H, Kunkel DD, Martin TM, Schwartzkroin PA, Tempel BL (1993) Heteromultimeric $\mathrm{K}^{+}$channels in terminal and juxtaparanodal regions of neurons. Nature 365:75-79.

Wu VM, Yu MH, Paik R, Banerjee S, Liang Z, Paul SM, Bhat MA, Beitel GJ (2007) Drosophila Varicose, a member of a new subgroup of basolateral MAGUKs, is required for septate junctions and tracheal morphogenesis. Development 134:999-1009.

Yang Y, Ogawa Y, Hedstrom KL, Rasband MN (2007) betaIV spectrin is recruited to axon initial segments and nodes of Ranvier by ankyrinG. J Cell Biol 176:509-519. 